\title{
Equity Fund Managements Promise and Action A Comparative Study of Nordic and US Fund's
}

\author{
Preuss, Bjørn
}

Document Version

Accepted author manuscript

Published in:

Journal of Behavioral and Experimental Finance

DOI:

10.1016/j.jbef.2019.05.007

Publication date:

2019

\section{License \\ CC BY-NC-ND}

Citation for published version (APA):

Preuss, B. (2019). Equity Fund Managements Promise and Action: A Comparative Study of Nordic and US

Fund's. Journal of Behavioral and Experimental Finance, 23, 84-89. https://doi.org/10.1016/j.jbef.2019.05.007

Link to publication in CBS Research Portal

\section{General rights}

Copyright and moral rights for the publications made accessible in the public portal are retained by the authors and/or other copyright owners and it is a condition of accessing publications that users recognise and abide by the legal requirements associated with these rights.

Take down policy

If you believe that this document breaches copyright please contact us (research.lib@cbs.dk) providing details, and we will remove access to the work immediately and investigate your claim. 


\title{
Equity Fund Managements Promise and Action: A Comparative Study of Nordic and US Fund's
}

\author{
Bjorn Preuss \\ Journal article (Accepted manuscript*)
}

\begin{abstract}
Please cite this article as:
Preuss, B. (2019). Equity Fund Managements Promise and Action: A Comparative Study of Nordic and US Fund's. Journal of Behavioral and Experimental Finance, 23, 84-89.

https://doi.org/10.1016/j.jbef.2019.05.007
\end{abstract}

DOI: 10.1016/j.jbef.2019.05.007

* This version of the article has been accepted for publication and undergone full peer review but has not been through the copyediting, typesetting, pagination and proofreading process, which may lead to differences between this version and the publisher's final version AKA Version of Record.

Uploaded to CBS Research Portal: May २०२०

(C) 2019. This manuscript version is made available under the CL-BY-NC-ND 4.0 license http://creativecommons.org/licenses/by-nc-nd/4.0/ 


\title{
Equity Fund Managements Promise and Action: A Comparative Study of Nordic and US Fund's*
}

\author{
BJOERN PREUSS ${ }^{\dagger}$
}

\begin{abstract}
The paper presents the differences in how fund managers in the Nordics and the US communicate towards investors. The work suggests that similarity of communicated values and actual action of the fund is a key driver to increase fund flow. It helps to sustain assets under management while uniting the picture a potential investor has of the fund. This action might lower the inherent risk in miss-communication. The analysis is building on textual statements of 80 equity funds from the Nordic countries and the US. We compare the funds of the two regions along factors which are according to recent research main drivers of investors when deciding if to invest in a fund or not. With this analysis, we aim to see the difference in the communicated values and the actual action of equity funds. By advancing the understanding of the coherence of communication in the Nordic region we aim to give implications for future research as well as advice to the practitioner.
\end{abstract}

\footnotetext{
*The paper got published in a short version as part of the research report of the project Nordic Finance and the Good Society at the Copenhagen Business School (2019). The full version of the paper got published in the Journal of Experimental and Behavioural Finance from Elsevier in 2019

${ }^{\dagger}$ Mr. Preuss is with the Department of International Economics and Management at Copenhagen Business School and with the Department of Economics at Radboud University Nijmegen
} 


\section{Does it matter what fund manager communicates and what they do?}

The recent past has created major challenges for the Nordic financial institutions. Regulations, as well as competition from major international players, have influenced the sector in the Nordic countries. This change impacts the sector's ability to sustain assets under management. Plus, the changed environment requires different skills from fund managers.

The ability to increase and sustain assets under management is a core skill for fund managers, as stated by Kacperczyk, Nieuwerbrugh, and Veldkamp (2014). According to research from Sensoy (2009), several factors like performance and risk exposure impact fund flow. However, softer facts like marketing related issues and communication towards market participants become increasingly important. If a fund is associated with high growth and an investment trend, this association leads to an increase in assets under management. Sensoy (2009) showed that the benchmark index of a fund is impacting whether investors invest in a fund or not. He showed that fund managers communication matters in the short run. However, in the long run, the communicated values must fulfill investors expectations. Without fulfilling expectations, the fund will not sustain the assets under management and has an outflow of funds Sensoy (2009).

This finding holds for all equity funds. However, Kacperczyk et al. (2014) showed that some funds act according to their communicated values, whereby, other funds do not.

Motivated by this difference, we analyzed Nordic and US equity funds. We investigate to what extent their communicated values are in line with their actions. To achieve the goal, we incorporated into our study, elements of text mining and machine learning models. The outcome of the text mining process can be compared with data from the funds. By using this approach, we give evidence about how similar the actions 
and the communications are. At its core, this paper examines which differences exist between the Nordic and the US funds. The communicated actions will be compared with the actual actions that the funds' take. This comparison will indicate to what extent the funds fulfill their communicated goals like profitability or stability. Based on the analysis, this study shows fund managers how communicated values help to sustain the assets under management.

\section{Financial Market Communication and Implications for Fund Flow}

Today, companies have more communication with the stock market than ever before. According to Goodman (2006), corporate communication is an important success factor for companies. van Woerkum and Aarts (2008) state that communication towards the financial markets became a central aspect of strategic operations. This statement holds especially true for funds. It impacts the funds' corporate success, but also decreases information asymmetries. By lowering information asymmetries, it helps to allocate resources efficiently (Yang, Kwak, Kaizoji, and Kim, 2008). Corporate proclamations will decrease the risk for the funds, which is estimated by investors and analysts (Diamond and Verrecchia, 1991). This lower estimated risk will result in lower costs for equity and debt that investors and creditors provide to the company (Botosan and Plumlee, 2002). As a result, the assets under management will increase. The communication to capital markets becomes especially important for funds because their business model is built upon the capital that they can invest. Through globalization, we see increased mobility of capital, which can impact a funds flow of capital significantly (Ahmed and Zlate, 2014).

Multiple scholars did early work in the field of fund-flow and management actions 
to increase assets under management (Ippolito, 1992) (Chevalier and Ellison, 1997) (Sirri and Tufano, 1998). In their studies, they examined that fund performance has an inherent influence on increasing fund-flow. Which is similar to attract assets under management. This relationship has been talked about since it has been shown that increasing profitability leads to a higher increase in assets under management as opposed to decreases in assets when profits declined (Chevalier and Ellison, 1997) (Sirri and Tufano, 1998).

Besides profitability factors, risk factors were important in the work of Brown, Harlow, and Starks (1996) as well as in the one from Chevalier and Ellison (1997). Their work showed that risk influences fund flow. Recent studies went beyond the simple analysis of flow-profit relationships. They showed that both the inflow and outflow of funds are related to the risk of the fund (Clifford, 2013).

Besides the profit and risk factors, softer marketing-related factors tend to have an impact on assets under management (Sensoy, 2009). In his work, Sensory (2009), showed that US equity funds tend to use indices as benchmarks that did not match the funds investment style. However, they incorporated a trendy area of investments. This association with trends leads to more flow despite the actual investment style of the fund. (Cooper, Gulen, and Rao, 2005)

In a recent working paper, Agarwal, Green, and Ren (2015) demonstrated that professional investors tend to use more sophisticated methods to attract capital. This circumstance is especially the case when they invest in the hedge fund industry Agarwal, Green, and Ren, 2016). Further factors that had a relationship to fund asset inflow were management compensation derived from fees. This relation is presented by the work of Berk and Van Binsbergen (2015). 


\section{Organizational Cultural Values}

Hence, marketing-related facts might play a significant role in attracting assets under management, and culture might play a role as well. Researchers and practitioners often define culture as a system of values, beliefs, and assumptions that are shared among people (Hofstede, 1983). Culture is, to a large extent, influencing how people interact organizationally or professionally (Rosenblatt, 2011) (Migliore, 2011) (Weber, Shenkar, and Raveh, 1996).

To explain and measure culture, frameworks such as the one of Hofstede (1983) and House et. all (2002) got established. The two frameworks started with a focus on country-specific culture, and at a later stage, added organization focused concepts. The focus on the specific values of organizations has been presented in papers from other researchers, like Gagliardi (1986) and Schein (2010). Multiple researchers analyzed the impact of culture on organizations in recent times including WarnerSøderholm (2012). Studies focusing on specific corporate processes such as mergers and acquisitions also presented a relationship between the organizational culture and the profit derived from the transaction (Janson, 1994). However, those studies do not elaborate on specific cultural elements rather they discuss the differences in cultures between two organizations. Given this fact, most elements of organizational culture remain unexplored (House, Javidan, Hanges, and Dorfman, 2002).

In addition to this discussion, Schwartz (1992) added that organizational values are related, but are different from individual, cultural and societal values (Schwartz, 1992). The differences in how culture is seen, but also measured, in research lead to the application of a new methodological approach which was elaborated in detail by Preuss (2017). 


\section{Method}

To analyze a funds communication and to compare it with the funds actual actions, we used text mining and machine learning techniques to quantify textual data. This textual data contains the content of a funds communications with investors. For the interpretation, we compared these communicated values with the actual actions of funds and examined differences between Nordic and US funds.

\section{A. Data sample of funds}

To compare Nordic and US fund managers, we incorporated equity funds from the Nordic region as well as US-based equity funds into the sample. The sample of funds being used in this study can be summarized by the following table I describing the region, the vendor as well as the number of represented funds:

Table ICovered funds by institution and region.

\begin{tabular}{ccc}
\hline Region & Name & Number of funds \\
\hline Nordics & Carnegie & 12 \\
Nordics & SEB & 12 \\
Nordics & Swedbank & 2 \\
Nordics & JYSKE bank & 3 \\
Nordics & Danske Invest & 8 \\
USA & JP Morgan & 22 \\
USA & Goldman Sachs & 13 \\
USA & Franklin Templeton & 8 \\
\hline
\end{tabular}


For the funds, textual data, in the form of fact sheets and marketing material was collected, which was later processed and analyzed using machine learning and keyword search. For each fund ca. 2-4 statements about their strategy and the followed investment approach have been used. Those statements are named fact sheets and are in terms of length and content comparable. In addition, relevant information describing the funds was collected. According to recent research, this information is relevant to investors to help them make investment decisions. Because of this relevancy, it influences a fund manager's flow of funds.

The next table shows collected metrics describing the funds return and risk. 1

Table IIFunds return and risk

\begin{tabular}{cccc}
\hline Variable & $\min$ & $\max$ & avg \\
\hline Performance 1y & -40 & 34 & 4.87 \\
Performance 3y & -80 & 113 & 29.49 \\
Morning star rating & 2 & 5 & 3.86 \\
Risk rating & 3 & 7 & 5.74 \\
\hline
\end{tabular}

We use these criteria at a later stage to compare the US-institutions to the Nordic institutions. We will, furthermore, link the information to the communicated values from the textual statements.

\footnotetext{
${ }^{1}$ Notes: The performance $1 \mathrm{y}$ measure was the average return of the funds in 2016 ; the performance $3 y$ is the average return of the funds in the years 2013-2016; the morning star rating represents the rating that the fund got from the morning star platform and the risk rating is the reported risk of the fund published by morning star.
} 


\section{B. Text Processing}

The sample contained textual statements that described the funds' actions and their communicated strategies. Hence, the data is present in the textual form. Some issues arise when analyzing them. To analyze the statements quantitatively a new set of methods is required. Mostly textual data are used in qualitative studies. Using it in quantitative analysis creates the need to transform the data. This step is called natural language processing or text processing. Text processing uses algorithms that read the textual statements and create a matrix out of the words and the n-grams (combinations of words that occur together). An example is presented in table III.

Table IIIExample of word matrix

\begin{tabular}{ccccc}
\hline & & & & \\
& income & ongoing & institutional & $\ldots$ \\
\hline SEB & 3 & 2 & 0 & $\ldots$ \\
JPM & 2 & 1 & 3 & $\ldots$ \\
$\ldots$ & $\ldots$ & $\ldots$ & $\ldots$ & $\ldots$ \\
\hline
\end{tabular}

In the case of this study, the text processing was performed by Python libraries and specifically the nltk library. In the following steps, the text gets changed to create a clean word matrix. To make the matrix, the words contained in the texts get processed to make them homogeneous. This process includes the stemming of the words, a step for reducing stop words, which are irrelevant to the specific content. The last step is to transform the words to the lower class meaning that all words are made uniform, written in small letters. 


\section{Unsupervised Learning and Keyword Search}

It is essential to make sense out of the processed words contained in the word matrix (Thawonmas, Sakamoto, Mizobuchi, and Yoshioka, 2005). We mapped in the first step the values to clusters. This was done by using an unsupervised clustering algorithm (Dutt, Aghabozrgi, Ismail, and Mahroeian, 2015). We applied a similar approach like Preuss (2017). The unsupervised approach enables the researcher to start with the data and apply a study design that explores the data. This way of research makes it possible to derive new insights into qualitative and fuzzy research fields such as culture or in specific communicated values of equity funds. Under the family of unsupervised learning algorithms, there are different options like $k$-means, fuzzy-c-means or the nearest - neighbor algorithm (Fahad, Alshatri, Tari, Alamri, Khalil, Zomaya, Foufou, and Bouras, 2014). In this analysis, we used $k$-means. $K$-means assembles the observations of the data set around the theoretical mean of a group of similar observations. It is based on the observations $\left(x_{1}, x_{2}, \ldots, x_{n}\right)$ with each observation is a $n$ dimensional vector. It clusters the observations into clusters $k<=n$ whereby the number of clusters is smaller than the number of observations. $S=S_{1}, S_{2}, \ldots, S_{k}$ this is done by minimizing the sum of squares within the clusters.

$$
\frac{n}{\operatorname{argmin} S} \sum_{i=1}^{k} \sum_{x \in S_{i}}\left\|x-\mu_{i}\right\|^{2}=\frac{n}{\operatorname{argmin} S} \sum_{i=1}^{k}\left|S_{i}\right| \operatorname{Var} S_{i}
$$

$\mu_{i}$ is, in this case, the mean point of $S_{i}$. The approach is like minimizing the square deviation of points in a cluster.

$$
\frac{n}{\operatorname{argmin} S} \sum_{i=1}^{k} \frac{1 !}{2\left|S_{i}\right| !} \sum_{x, y \in S_{i}}\|x-y\|^{2}
$$

The total variance is constant and with that, the procedure is equivalent to maximizing. 


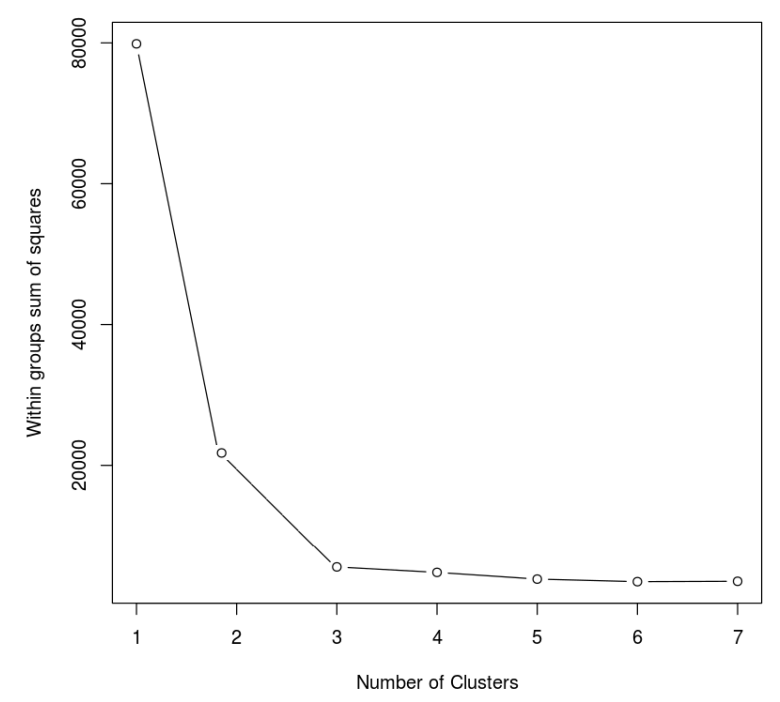

Figure 1. Plot of optimal number of clusters

$$
\sum_{x \in S_{i}}\left\|x-\mu_{i}\right\|^{2}=\sum_{x-y \in S_{i}}\left(x-\mu_{i}\right)\left(\mu_{i}-y\right)
$$

The incoming observations are clustered based on their similarity. We used the Python library sklearn to construct and run the model. In the end, we see which values are more influential in a certain cluster. This enables us to draw a conclusion on the values that distinguish the communication from the different funds.

The number of clusters was set by applying the elbow method Goutte, Toft, Rostrup, Nielsen, and Hansen (1999). With this we can select the optimal number of $k-$ mean clusters by the percentage of variance explained as a function of the number of cluster. Goutte et al. (1999) Now the cluster gets chosen by which adding another cluster would not add much additional value to explain the variance in the under laying data. The outcome of the analysis can be seen in figure (1).

We can see that the curve gets not clearly interrupted but flattens out after two 
clusters. The graphic (1) indicates that a selection of two clusters is the optimal number to describe most of the variance contained in the data set. Hence this, the number of clusters for this $k$-means algorithms was set at two.

A keyword search was completed on top of the unsupervised learning algorithm, to define textual statements. The method can be applied to databases or on fuzzy data sets (Hristidis, Papakonstantinou, and Gravano, 2003) (Li, Wang, Wang, Cao, Ren, and Lou, 2010). Because the textual statements have a high variety, we propose that there was a fuzzy element in the keyword search. That means that associated words or word stems also need to be considered. With this data, we describe which emphasis lies in the communication of a specific area. We incorporated into our text mining approach the options of the nltk python library to search for acronyms for certain word (Liu, Liu, and Huang, 2017). With this approach we covered the whole variety of the communication towards a specific concept.

To test the evidence we got from the text mining research, we asked a few fund managers about their view on the main findings at the end. This step was done by framing the core findings of the research into questions and asking the fund managers if those statements hold from their practical experience. The questions asked can be found in the appendix of this paper.

\section{Critical Differences in Fund Managers Communication}

In this study, we examined the differences between the Nordic and US funds. We used different variables as well as quantified textual information. We linked the textual data to variables that describe the actual performance and actions of a fund. In the first step of the analysis, we applied the clustering algorithm $\mathrm{k}$ means to see whether 
the textual information contains a link between the clusters and the country of origin of the funds. The results are represented in table IV.

Table IVClusters and regional split

\section{Cluster Percent Nordic Percent US}

\begin{tabular}{ccc}
\hline No1 & 100 & 0 \\
No2 & 0 & 100 \\
\hline
\end{tabular}

By applying the cluster analysis we see a clear differentiation between the communicated values of Nordic funds and the US funds. The unsupervised cluster analysis differentiates the content from the statements exact like their country of origin (all statements in cluster No1 are Nordic and all in No2 are from the US). One reason for this difference could be cultural/national norms that differentiate the Nordic region from the US region. A critical point could be that some of the official statements are influenced by legal standards which require funds to communicate in specific ways. This critical point could eventually lead to a limitation of this study.

However, we assume a steady influence of the legislation on funds in different markets. Hence this we see it not as a driving factor in the differences. This perspective allows us to let this factor fade into the background. Following the findings of contemporary research, we see indications that regardless of the legal system, fund managers tend to communicate in ways that they perceive as a right to increase and sustain their assets under management. This might be with all changes of legislation constant.

Presenting this distinction between the Nordics and the US leads us to the question, what are the main differences in communicated messages between the regions? For this step, we investigated the word stems contained in each cluster and listed the 
top influential words in the two clusters. The words are presented in the following information as word clouds.

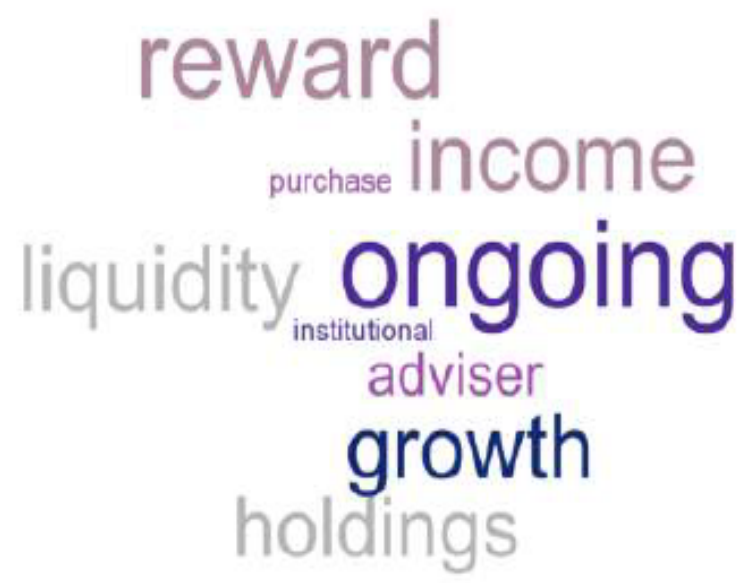

Figure 2. Word cloud top Words Nordics

One main conclusion we draw out of this analysis step is that the Nordic asset managers seem to communicate values like "ongoing", "reward", "growth" and "income". This is displayed in figure 2. These values can be referred to private investors that are seeking stable growth investment intending to generate an income. The words "advisor" or "institutional" as a word stems are far less often used in the communication. The questions we asked to fund managers after the analysis indicated that Nordic institutions are engaged in the long term with their clients and see them as partners (SparInvest, 2017) (Analythics, 2017). In contrast, how US funds and asset managers communicate shows a different weighting on these words in figure 3 


\section{purchase income \\ institutional adviser iligundidy reward holdings growth}

Figure 3. Word cloud top Words US

The most used word is "institutional". This fact refers to a high degree of institutional investing. Other research has shown that the main investments in stocks and equity funds in the US are held by institutional investors.

In contrast to the Nordics, This situation might require in itself a different way of communicating.

Furthermore, "adviser" and "purchase" are core parts of the communicated values of US funds. Both can be linked to a strong sales culture in the U. S., where the way that Nordic managers sell is less direct. In the Anglo-Saxon world, the communication of purchasing and buying is much stronger than can be found in Europe. The question is whether this will change in America, having a stronger influence on the people in Europe and especially in the Nordics. The analysis revealed a further finding for the Nordics. Nordic equity funds communicated a significantly higher number of country and region names than their US peers, see for this figure 4 


\section{sweden \\ swedish $h_{\substack{\text { toreign } \\ \text { nordic }}}$ danske}

Figure 4. Word cloud Country Names Nordic Funds

When looking at the number of communicated regions or country names, the US funds tend not to communicate their country of origin in their textual statements. In contrast, Nordic fund managers do it regularly. The fact that Nordic institutions communicate more frequently about their country of origin could lead to the interpretation that the Nordic countries transport values which are positive among investors. The questions that were asked to fund managers from the Nordics reveal that the fact that the fund is allocated in one of the Nordic countries is seen as positive (SparInvest, 2017)) (Capital, 2017).

All in all, we see a clear difference in communicated information between the Nordics and the US. The clear distinction between both fund groups by region and by communicated values, lead us to the question of how the two groups differ in terms of following what they have promised.

Building on the studies of fund flow, it is relevant to test the differences between communicated values and actual actions along with the influence factors of fund flow. Current research points out that the profitability of funds influences a funds ability to increase and maintain the assets under management. This fact leads to the first comparison of how much emphasis funds put on communicating profitability versus reaching a certain level of profits, table $\mathrm{V}$ 
Table VComparison Alongside Profitability

\begin{tabular}{ccc} 
& USA & Nordic \\
\hline Avg Performance 1y & 0,30 & 7,54 \\
Avg Performance 3y & 23,20 & 33,15 \\
Communication Profitability & 44,90 perc. & 55,10 perc.
\end{tabular}

The analysis reveals that Nordic funds communicate more profitability values, then US funds and reach in a one-year as well as during three years higher performance levels than their US peers.

The next factor that, according to Sensoy (2009), influences whether a fund can increase the flow and sustain it, is the risk factor. The next table $\mathrm{VI}$ presents the morning-star risk rating as average for the underlying funds of the two regions and compares it with how much emphasis funds put on communicating the factor risk.

Table VIComparison of Difference in Risk Communication and Exposure

USA Nordic

Risk communication 42,19 perc. 57,81 perc.

\begin{tabular}{lll} 
Risk rating & 6,1 & 5,5 \\
\hline
\end{tabular}

This step shows an ambivalent result. Although the Nordic funds have lower risk ratings on average compared to the US funds, most funds from the Nordics communicate more values associated with risk. This finding leads to the question why the 
Nordics have a lower level of risk represented in this analysis by the morning-star risk rating but also a higher awareness of risk. The finding could imply that the higher risk awareness of Nordic funds leads to a lower rating of risk exposure by third parties. This higher awareness might be driven by legislation or by the potential investor base which also shows a higher awareness of risk than its US counterpart. This interpretation is, however, not supported by further analysis and, despite these suggestions, are possibilities for future research.

Whereas current research had a closer look at funds risk and investment style, it also stated that there is an influence of the study period. Where some communication strategies lead to an increase in fund flow towards the fund in the short run, the data show a decline in assets under management in the long run. This fact is often the case when communicated values are not coherent with the funds actual actions. This statement leads to the next analysis step (table $\overline{\mathrm{VII}}$ ) in which the communication of long-term values gets compared with the fund rating from morning-star which aims to select long- term profitable funds that are of high quality.

Table VIIComparison of Long term Orientation

\begin{tabular}{ccc}
\hline & USA & Nordic \\
\hline Morning-star rating & 3 & 4 \\
Long term communication & 34,72 perc. & 65,28 perc.
\end{tabular}

The table presents data that lets us conclude, that both from a rating perspective as well as from their communicated values, Nordic funds are more long-term oriented than their US peers. While having Nordic institutions opt for higher levels of profit, it is an interesting finding that the same funds also have a higher degree of risk communication 
compared to the US funds. These phenomena work well together because according to economic theory, higher profitability must go with a higher risk. Having this fact in mind, it is logical to communicate both facts similarly.

Nevertheless, it could be because of the influence of some legal requirements, that those Nordic institutions are forced to a greater extent to include the risk element in their communication. When linking this information to findings about general organizational values from scholars like Hofstede and House, the future orientation of Nordic citizens goes hand in hand with a high degree of legal security levels and well-fare system (Hofstede, 1984) (House et al., 2002). This finding, as well as others, lead both to advise regarding flow enhancement as well as imply some points that can be addressed in future research.

\section{Implications for Fund Flow Enhancement}

Understanding that the communication of fund managers who seek increasing fund flow is a neglected field of research. However, we see it as relevant to understanding how funds market themselves because psychology seems to have a large impact on investment decisions and concepts like the homoeconomicus have been criticized re-

cently (Shiller, 2000). Hence, we see the communication of fund managers is relevant. The study reveals that there is a clear distinction between the communicated values of Nordic and US fund managers. Also, the degree to which their communicated values are coherent with their actual actions differs.

We see in Nordic institutions, a stronger focus on communicating long-term values compared to US funds. The communication of Nordic funds is more orientated towards the private investor who seeks the stable, long-term growth of his assets, where US funds target mainly institutional investors. One interesting finding was that Nordic funds 
tend to communicate their country of origin much more than US funds. This finding was backed up by active fund managers who confirmed that having their origin in a Nordic country is widely seen as a positive factor. By communicating the country of origin, the fund aims to transport the positive values and image that the Nordic region has globally. When looking at differences between the communicated values and the actual actions of the funds, it can be said that Nordic funds show more of consensus between the communicated values and the actual action whereby US funds tend to design their communication by focusing more on high growth and profitability even if their performance was lower compared to Nordic institutions.

We suggest that fund managers orientate their communication on their actual actions as well as to focus on the values that are at the core of their operations. If those are Nordic values, then the fund should focus on this fact and could to some extent increase its image regarding long term focus and low risk.

As concluding remarks, there is still much to do and to research in the field of organizational communication and specifically around funds communication towards investors as well as the capital markets.

\section{Suggestions for Future Research}

We showed some interesting points by presenting this comparison of Nordic and US equity funds from a different angle. This fact leaves room for future research and opens up new questions. Since the financial industry is more regulated than others, indications are that legal frameworks could have an influence on how fund managers communication with investors. This situation leads to the conclusion that legal frameworks might have an impact on the values which are being communicated. This fact may point out some limitations of this study because it analyses the actual 
communicated values of funds in two different legal environments. A future research approach that tries to incorporate the differences between legal systems and their influence on the communicated values might, therefore, be suitable. Furthermore, we propose that future research should examine which specific communicated values drive investors. This study has been constructed on recently-stated relevant factors and has analyzed how those values are communicated. However, in the current research, those factors are derived from the historical values describing a fund and were not only focused on the communication itself.

Another area where we suggest more research should happen is the field of text analysis and its application in researching organizational values. Since most of the available data are text-based, it opens an interesting field of research to access data regarding softer facts that influence an organization. We have, in this paper, used a method that inherits unsupervised algorithms as well as a keyword search. However, the fast-evolving areas of machine learning, deep learning, and reinforced learning are worth putting more research emphasis on. The softer social sciences should especially profit from this technique for the analysis of qualitative data on a larger scale. 


\section{Appendix}

To back up the core findings of this paper, fund managers were asked if they could see these tendencies in their day to day work. The following list represents the asked questions based on the research findings:

1. Would you say that your fund communicates unique values in order to differentiate your investment strategy from other funds?

2. How much is your fund focused on long-term orientation in the investment process?

3. Does that match the investor profile that you have as a target?

4. Which role plays the risk of investments in the communication of your fund and would you describe your investors as risk averse?

5. Does the country of origin play a role in your communication/sales process?

6. Would you say that communication towards investors became more important in recent years? 


\section{REFERENCES}

Agarwal, Vikas, T Clifton Green, and Honglin Ren, 2016, Alpha or beta in the eye of the beholder: What drives hedge fund flows? .

Ahmed, Shaghil, and Andrei Zlate, 2014, Capital flows to emerging market economies: A brave new world?, Journal of International Money and Finance 48, 221-248.

Analythics, Century, 2017, Interview about asset management communication Sweden (Interviewer Bjrn Preuss).

Berk, Jonathan B, and Jules H Van Binsbergen, 2015, Measuring skill in the mutual fund industry, Journal of Financial Economics 118, 1-20.

Botosan, Christine A, and Marlene A Plumlee, 2002, A re-examination of disclosure level and the expected cost of equity capital, Journal of accounting research 40, $21-40$.

Capital, Clavis, 2017, Interview about asset management communication Denmark2 (Interviewer Bjrn Preuss).

Chevalier, Judith, and Glenn Ellison, 1997, Risk taking by mutual funds as a response to incentives, Journal of Political Economy 105, 1167-1200.

Clifford, James, 2013, Risk and fund flows (Working Paper).

Diamond, Douglas W, and Robert E Verrecchia, 1991, Disclosure, liquidity, and the cost of capital, The journal of Finance 46, 1325-1359.

Dutt, Ashish, Saeed Aghabozrgi, Maizatul Akmal Binti Ismail, and Hamidreza Mahroeian, 2015, Clustering algorithms applied in educational data mining, International Journal of Information and Electronics Engineering 5, 112. 
Fahad, Adil, Najlaa Alshatri, Zahir Tari, Abdullah Alamri, Ibrahim Khalil, Albert Y Zomaya, Sebti Foufou, and Abdelaziz Bouras, 2014, A survey of clustering algorithms for big data: Taxonomy and empirical analysis, IEEE transactions on emerging topics in computing 2, 267-279.

Gagliardi, Pasquale, 1986, The creation and change of organizational cultures: A conceptual framework, Organization studies 7, 117-134.

Goutte, Cyril, Peter Toft, Egill Rostrup, Finn Å Nielsen, and Lars Kai Hansen, 1999, On clustering fmri time series, NeuroImage 9, 298-310.

Hofstede, Geert, 1983, The cultural relativity of organizational practices and theories, Journal of international business studies 14, 75-89.

Hofstede, Geert, 1984, Cultural dimensions in management and planning, Asia Pacific journal of management 1, 81-99.

House, Robert, Mansour Javidan, Paul Hanges, and Peter Dorfman, 2002, Understanding cultures and implicit leadership theories across the globe: an introduction to project globe, Journal of world business 37, 3-10.

Hristidis, Vagelis, Yannis Papakonstantinou, and Luis Gravano, 2003, -efficient ir-style keyword search over relational databases, in Proceedings 2003 VLDB Conference, 850-861, Elsevier.

Ippolito, Richard A, 1992, Consumer reaction to measures of poor quality: Evidence from the mutual fund industry, The Journal of Law and Economics 35, 45-70.

Janson, Lena, 1994, Towards a dynamic model of post-acquisition cultural integration 
Kacperczyk, Marcin, Stijn Van Nieuwerbrugh, and Laura Veldkamp, 2014, Timevarying fund manager skill, The Journal of Finance 69, 1455-1484.

Li, Jin, Qian Wang, Cong Wang, Ning Cao, Kui Ren, and Wenjing Lou, 2010, Fuzzy keyword search over encrypted data in cloud computing, in INFOCOM, 2010 Proceedings IEEE, 1-5, IEEE.

Liu, Jie, Caihua Liu, and Yalou Huang, 2017, Multi-granularity sequence labeling model for acronym expansion identification, Information Sciences 378, 462-474.

Migliore, Laura Ann, 2011, Relation between big five personality traits and hofstede's cultural dimensions: Samples from the usa and india, Cross Cultural Management: An International Journal 18, 38-54.

Preuss, Bjørn, 2017, Text mining and machine learning to capture cultural data, 10.13140/RG.2.2.30937.42080 .

Rosenblatt, Valerie, 2011, The impact of institutional processes, social networks, and culture on diffusion of global work values in multinational organizations, Cross Cultural Management: An International Journal 18, 105-121.

Schein, Edgar H, 2010, Organizational culture and leadership, volume 2 (John Wiley \& Sons).

Schwartz, Shalom H, 1992, Universals in the content and structure of values: Theoretical advances and empirical tests in 20 countries, in Advances in experimental social psychology, volume 25, 1-65 (Elsevier).

Sensoy, Berk A, 2009, Performance evaluation and self-designated benchmark indexes in the mutual fund industry, Journal of Financial Economics 92, 25-39. 
Shiller, Robert C, 2000, Irrational exuberance, Philosophy $\&$ Public Policy Quarterly $20,18-23$.

Sirri, Erik R, and Peter Tufano, 1998, Costly search and mutual fund flows, The journal of finance 53, 1589-1622.

SparInvest, 2017, Interview about asset management communication Denmark1 (Interviewer Bjrn Preuss).

Thawonmas, Ruck, Akio Sakamoto, Shinji Mizobuchi, and Masutatsu Yoshioka, 2005, Text mining method and apparatus for extracting features of documents, US Patent $6,882,747$.

van Woerkum, Cees, and Noelle Aarts, 2008, Staying connected: The communication between organizations and their environment, Corporate Communications: An International Journal 13, 197-211.

Warner-Søderholm, Gillian, 2012, Culture matters: Norwegian cultural identity within a scandinavian context, Sage Open 2, 2158244012471350.

Weber, Yaakov, Oded Shenkar, and Adi Raveh, 1996, National and corporate cultural fit in mergers/acquisitions: An exploratory study, Management science 42, 12151227.

Yang, Jae-Suk, Wooseop Kwak, Taisei Kaizoji, and In-mook Kim, 2008, Increasing market efficiency in the stock markets, The European Physical Journal B 61, 241246. 